\title{
Gold Recovery from a Gold Tailing by Floatation and Thiourea Leaching
}

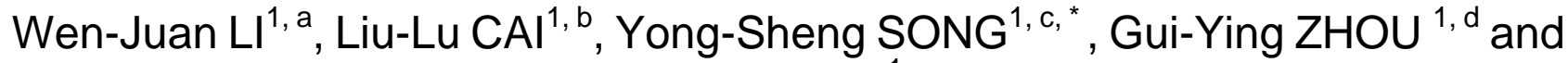 \\ Yong $\mathrm{CHEN}^{1, \mathrm{e}}$
}

${ }^{1}$ National Engineering Lab. of Biohydrometallurgy, General research Institute for Nonferrous Metals, Beijing 100088, China;

ajuanzi88888@126.com, bcailiulu_03@163.com, c46826273@qq.com,

zzhouguiying2001@163.com, ${ }^{\mathrm{e}} \mathrm{cy} 040311 @ 163 . c 0 m$

*Corresponding author

Keywords: Recovery, Tailing, Gold, Mineral liberation analyzer

\begin{abstract}
With the feature of high pyrite, high gold, fine gold dissemination in a gold tailing, experimental studies of floatation and thiourea leaching were carried out on a gold ore. The results showed that single floatation or thiourea leaching process was not suitable for this tailing. The grade and recovery of gold concentrate was $50.62 \mathrm{~g} / \mathrm{t}$ and $82.68 \%$ respectively by flotation with the particle size of -320 mesh $85 \%$. The thiourea leaching rate was $66 \%$ with the particle size of -320 mesh $85 \%$. The leaching rate was $89.24 \%$ by floatation- thiourea combined process. The particle size of the floation circuit and the tailing thiourea circuit was -320 mesh $85 \%$. The floatation-tailing thiourea leaching combined process was recommended to treat this ore.
\end{abstract}

\section{Introduction}

Successful concentration of gold in refractory sulfide ore is almost exclusively dependent on the association of the gold with the sulfides [1]. Although cyanide has been the primary lixiviant for the leaching of gold for over a century now, it is associated with certain shortcomings such as toxicity, long leaching times and considerable interaction with other nonferrous metals present in the gold ores. Because of this, attempts are being made by various investigators to search for alternative nontoxic lixiviants [2] for gold. One such leachant, thiourea [3] is known to give much faster dissolution of gold. The choice of process for refractory ores or concentrate treatment is based on many technical, economic, and environmental factors [4].

The feed used in this study is a gravity tailing which contains many kinds of minerals, such as gold, pyrite and pyrrhotite. The ore has the following features, which make it more difficult to recover valuable minerals: 1) a high content of Au precious metals in the head ore but various clayey gangue minerals exist in the head ore, including calcite, garnet, and white mica; 2) Part of the gold minerals were wrapped in the gangue minerals, and part of the gold mineral grains exist along the gangue fractures. The recovery of valuable metals from this ore would therefore be very difficult.

\section{Experimental}

\section{Materials, Reagents and Methods}

The tailing used was obtained from Africa. The tailing was homogenized and split into $1 \mathrm{~kg}$ representative sub-samples. During the ore preparation, a $100 \mathrm{~g}$ sub-sample was taken for head grade chemical analysis (see results in Table 1), which shows that the goal of the study is to recover Au. The tailing sample will be called the head ore or feed as follows. Collectors from the Xitieshan Lead-Zinc Mine were sodium butyl xanthate and ammonium dibutyldithiophoshate $\left(\left(\mathrm{C}_{4} \mathrm{H}_{9} \mathrm{O}\right)_{2} \mathrm{PSSNH}_{4}\right)$. Terpenic oil (also from Xitieshan Lead-Zinc Mine), with monohydric alcohol content above 50\%, was used as frother. Reagents were industrial grade and were diluted in water to $1 \%$. Other reagents purchased from Boenchuangqi Beijing Co., Ltd were chemical pure. 
A Mineral Liberation Analyzer (MLA) was used to characterize the feed and products. MLA analysis was performed on different size fractions to examine the mineralogy and mineral liberation. A chemical analysis of the feed was used to determine the distribution of Au in each size fraction. For the mineral composition and Au phase determination, see table 2 and 3. A SEM-backscattered electron (BSE) image and EDAX of Au mineral is shown in Figure 1.

Table 1 Multi-element analysis of head ore (\%)

\begin{tabular}{ccccccc}
\hline Element & $\mathrm{Au}^{*}$ & $\mathrm{~Pb}$ & $\mathrm{Zn}$ & $\mathrm{S}$ & $\mathrm{Fe}$ & $\mathrm{Ca}$ \\
\hline Content & 11.66 & 0.0033 & 0.0046 & 7.84 & 10.83 & 1.65 \\
\hline Element & $\mathrm{As}$ & $\mathrm{Sb}$ & $\mathrm{SiO}_{2}$ & $\mathrm{Al}_{2} \mathrm{O}_{3}$ & $\mathrm{Cu}$ & $\mathrm{Mg}$ \\
\hline Content & $<0.005$ & 0.0063 & 62.13 & 6.56 & 0.0032 & 0.53 \\
\hline
\end{tabular}

Note: the unit of $\mathrm{Au}$ is $\mathrm{g} / \mathrm{t}$.

Table 2 Distribution of major feed minerals from MLA (\%)

\begin{tabular}{|c|c|c|c|}
\hline Mineral & $\begin{array}{l}\text { Mass fraction } \\
(\% \mathrm{w} / \mathrm{w})\end{array}$ & Mineral & $\begin{array}{l}\text { Mass fraction } \\
(\% \mathrm{w} / \mathrm{w})\end{array}$ \\
\hline Au minerals & trace & quartz & 52.170 \\
\hline pyrite & 14.110 & dolomite & 2.760 \\
\hline pyrrhotite & 0.630 & calcite & 1.520 \\
\hline arsenopyrite & 0.005 & biotite & 11.560 \\
\hline magnetite & 5.610 & isinglass & 0.430 \\
\hline limonite & 0.730 & garnet & 0.950 \\
\hline covellite & 0.004 & augite & 0.590 \\
\hline chalcosine & 0.003 & else & 1.898 \\
\hline sodaclase & 7.030 & total & 100.00 \\
\hline
\end{tabular}

Table 3 Au phase determination results

\begin{tabular}{lllll}
\hline $\begin{array}{l}\text { Content and } \\
\text { distribution }\end{array}$ & $\begin{array}{l}\text { Cyanide leaching } \\
\text { gold }\end{array}$ & $\begin{array}{l}\text { Gold enclosed } \\
\text { in sulfides }\end{array}$ & $\begin{array}{l}\text { Gold enclosed } \\
\text { in gangue }\end{array}$ & Total \\
\hline Content (g/t) & 9.14 & 1.45 & 1.07 & 11.66 \\
Distribution (\%) & 78.39 & 12.44 & 9.17 & 100.00 \\
\hline
\end{tabular}

Note: 'Cyanide leaching gold' means Au can be leached by cyanide when the head ore ground to 90\% $-0.074 \mathrm{~mm}$. It is probably in the form of liberated gold, fissure gold or bare gold intergrowth with other sulfides or gangue. 'Gold enclosed in sulfides' means the remaining Au in leaching residue of pure sulfide mineral extraction. 'Gold enclosed in gangue' means the remaining gold excluding 'Cyanide leaching gold' and 'Gold enclosed in sulfides'. 


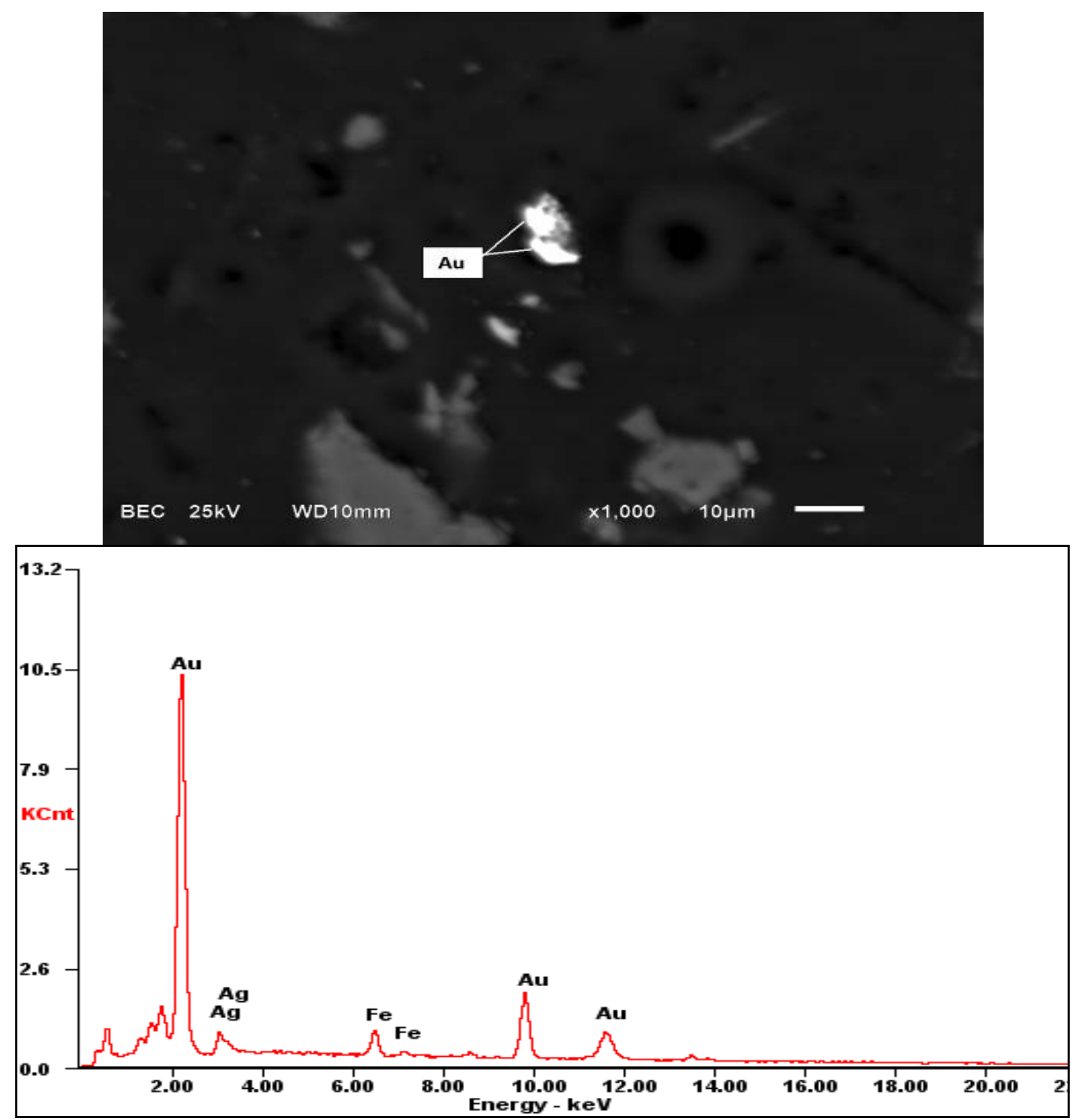

Fig. 1 Scanning electron microscope-backscattered electron (SEM-BSE) results

\section{Floatation}

The feed was processed with and without regrinding. For the closed circuit flow sheets and results, see figure 2 and table 4-5. 


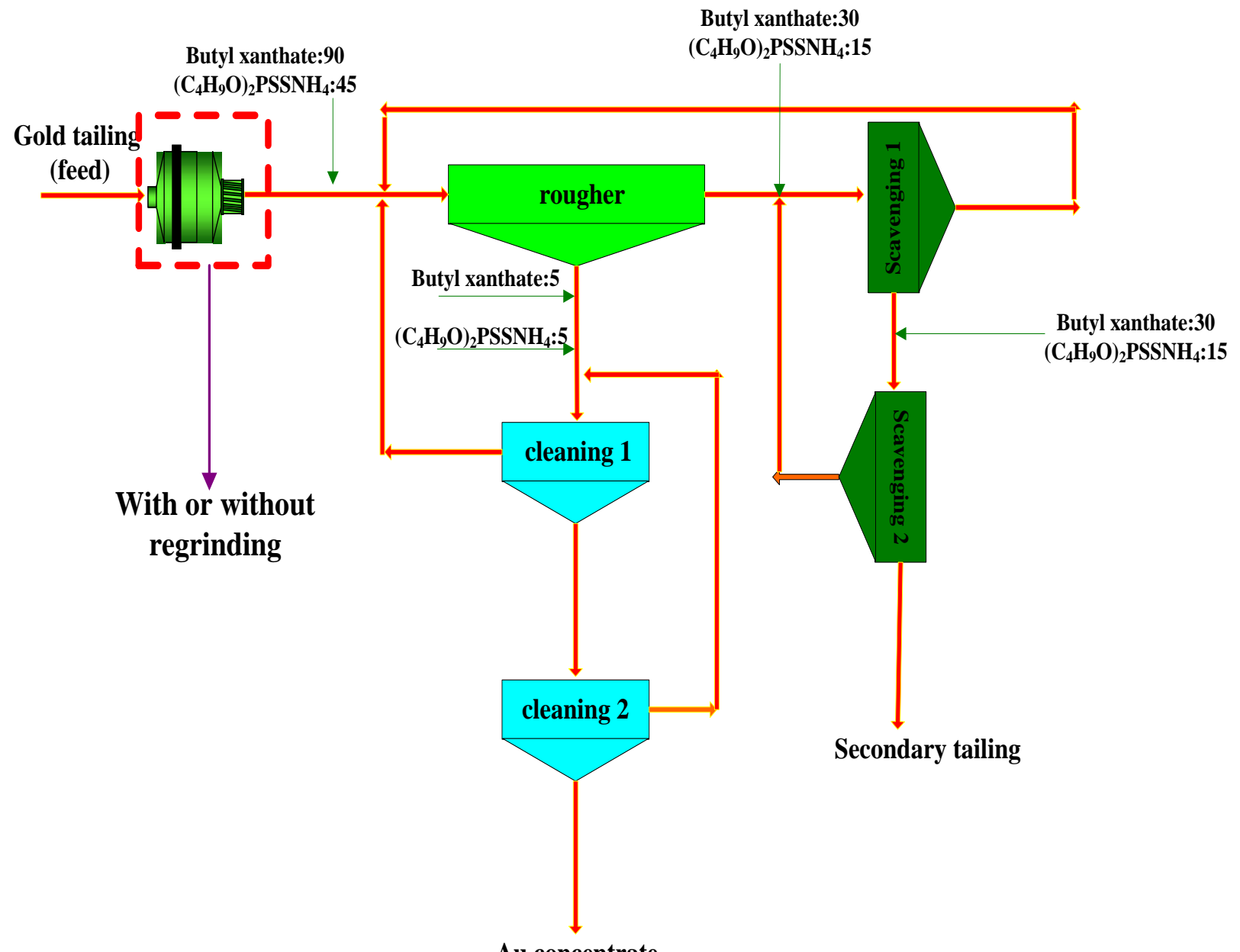

Au concentrate

Fig. 2 The closed circuit flow sheet with and without regrinding

Table 4 The closed circuit results without regrinding

\begin{tabular}{llll}
\hline Products & Yield(\%) & Au assay(g/t) & Au recovery \\
\hline Au concentrate & 14.60 & 57.21 & 68.92 \\
Secondary tailing & 85.40 & 4.41 & 31.08 \\
Tailing (feed) & 100.00 & 12.12 & 100.00 \\
\hline
\end{tabular}

Table 5 The closed circuit results with regrinding

\begin{tabular}{llll}
\hline Products & Yield(\%) & Au assay(g/t) & Au recovery \\
\hline Au concentrate & 19.45 & 50.62 & 82.68 \\
Secondary & 80.55 & 2.56 & 17.32 \\
tailing & 100.00 & 11.91 & 100.00 \\
Tailing (feed) & &
\end{tabular}

It can be noticed from table 4-5 that the Au concentrate obtained from the closed circuit without regrinding has higher Au grade but sharply lower Au recovery. It can be assumed that part of the Au grains exist as inclusions in the gangue and float with lower speed. The closed circuit flow sheet with regrinding was picked for its high recovery. The Au grade in the secondary tailing is still very high. The Au assays $2.56 \mathrm{~g} / \mathrm{t}$ in the secondary tailing which needs further processing. 


\section{Thiourea Leaching}

The floatation secondary tailing was leached by thiourea process. The leaching process flow sheet and results were shown in fig. 3 and table 6.

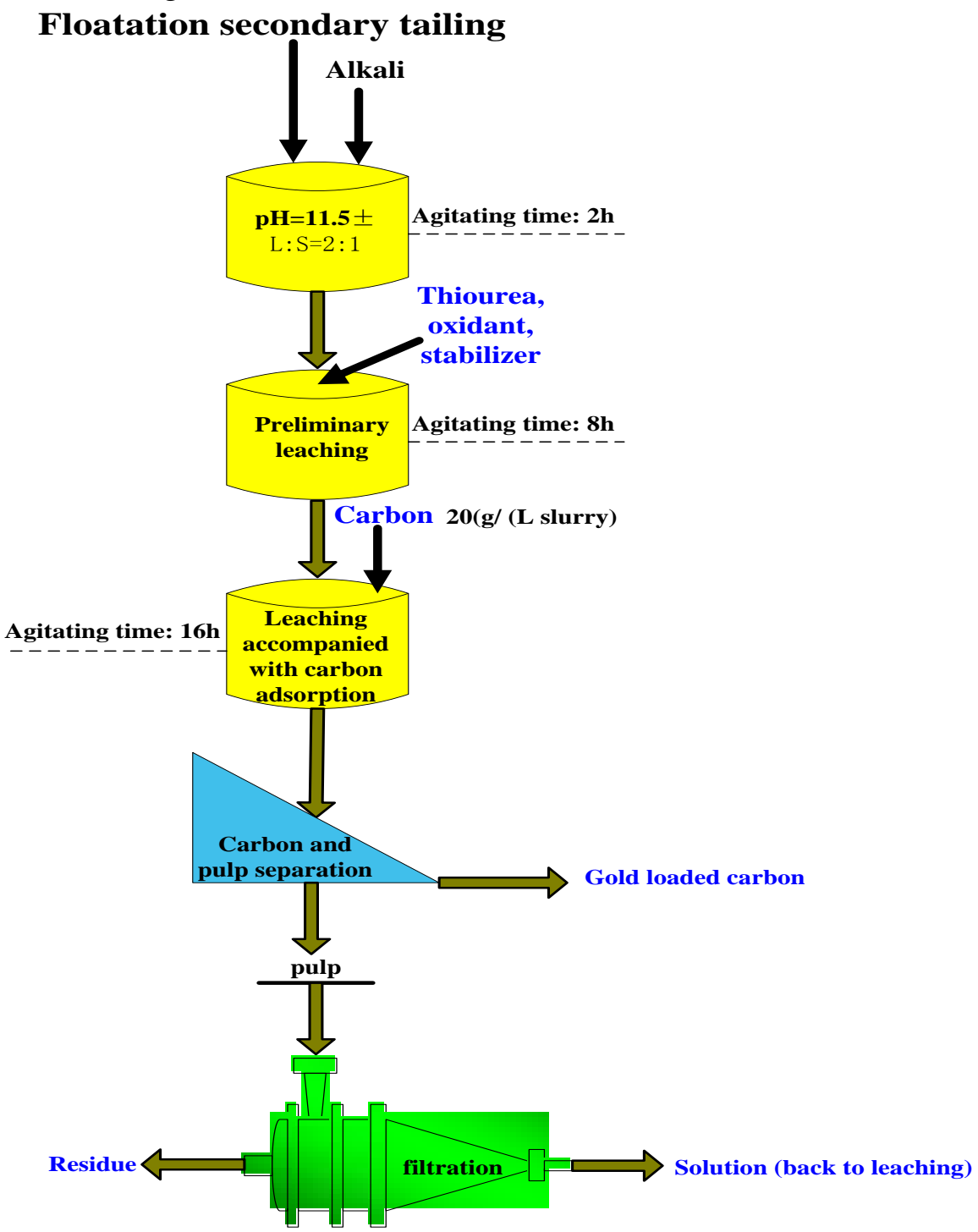

Fig.3 Thiourea leaching flow sheet 


\section{Quartz}
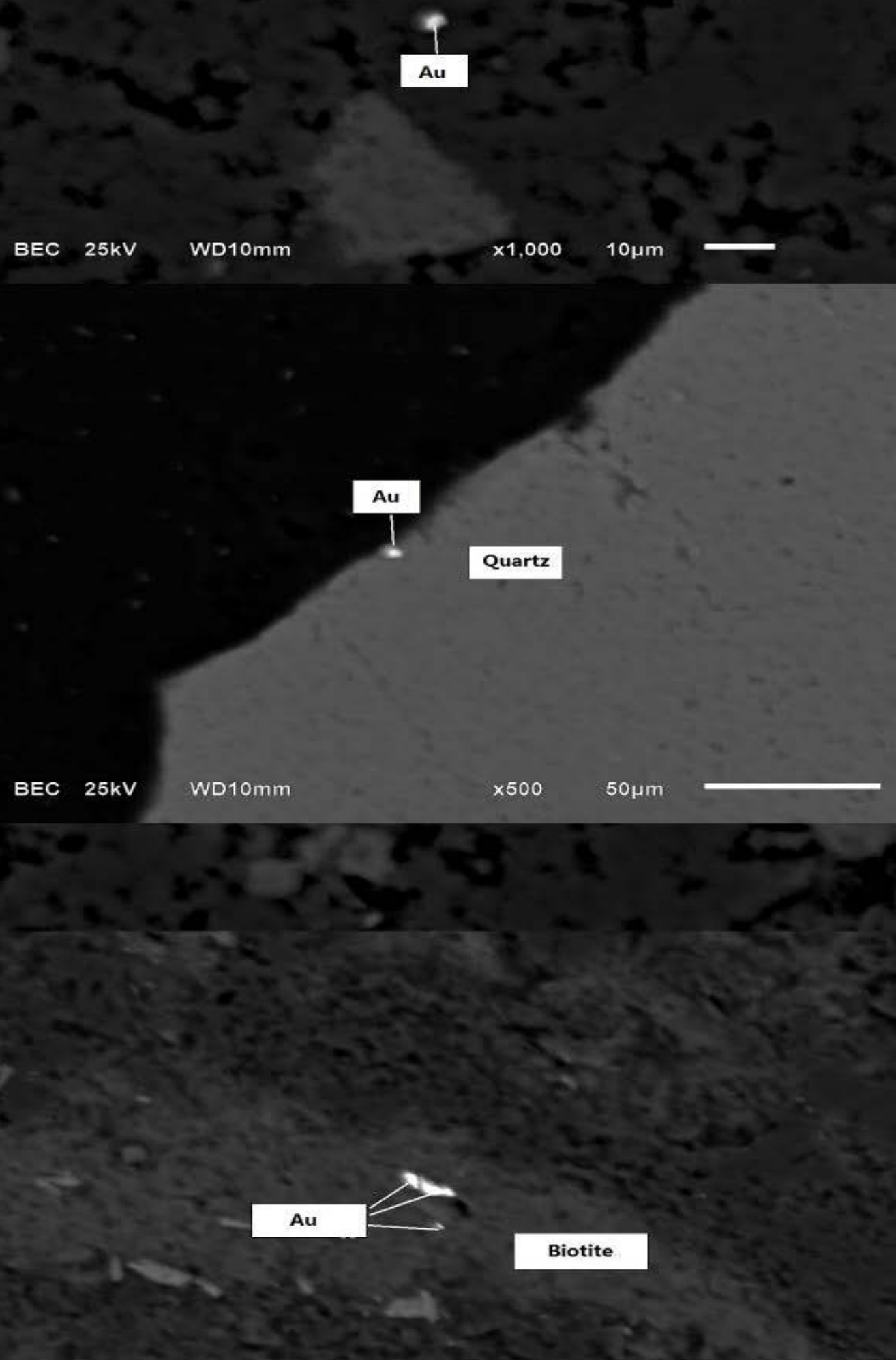

Fig. 4 The gold occurrence in the leaching residue 
Table 6 The closed circuit results with regrinding

\begin{tabular}{cccc}
\hline Products & Au assay(g/t) & Operation Au recovery(\%) & Au recovery to the feed(\%) \\
\hline Leaching residue & 1.59 & 37.89 & 6.56 \\
\hline
\end{tabular}

In order to determine the possibility of the further gold leaching in the leaching residue, the leaching residue was reground to -400 mesh $90 \%$. In result, there was little gold further leached. The leaching residue was detected through SEM, for the image, see fig.4, which illustrates that the gold exists as micron fine inclusions in the gangue.

\section{Summary}

The single floatation or thiourea leaching process was not suitable for this tailing. The floatation-tailing thiourea leaching combined process was recommended to treat this ore.

\section{Acknowledgements}

This research was financially supported by National Natural Science Foundation of China (51504031).

\section{References}

[1] Bulatovic, S.M., 1997. Flotation behaviour of gold during processing of porphyry copper-gold ores and refractory gold bearing sulfides. Miner. Eng. 10(9), 895-908.

[2] Swaminathan, P., Pyke, P., Johnston, R.F., 1993. Reagent trends in the gold extraction industry. Miner. Eng. 6 (1), $1-16$.

[3] Brent Hiskey, J., 1984. Thiourea leaching of gold and silver. Practical Hydrometallurgy 1983. SME-AIME, New York,pp. 95- 99.

[4] S. Ubaldini, F. Veglio, F. Beolchini, L. Toro,C. Abbruzzese. Gold recovery from a refractory pyrrhotite ore by biooxidation. Int. J. Miner. Process. 602000 247-262. 